\title{
AVALIAÇÃO DA PRODUTIVIDADE DOS POÇOS TUBULARES NA SUB-BACIA DO JUQUERI-CANTAREIRA/SP
}

\author{
Marcio Costa Abreu ${ }^{1}$; Bruno Pirilo Conicelli ${ }^{2}$, Jorge Ramón Peñaranda ${ }^{2}$
}

Resumo: As águas subterrâneas são importantes fontes de suprimento complementar de água na sub-bacia do Juqueri-Cantareira, localizada na região metropolitana de São Paulo/SP, sendo utilizada por grande número de usuários para as mais diversas finalidades. Por esse motivo, esse trabalho tem como objetivo contribuir para o conhecimento da produtividade dos poços tubulares e, respectivamente, dos sistemas aquíferos inseridos nessa área. Para isso foram avaliados os parâmetros hidráulicos disponíveis de 189 poços tubulares, os quais indicam vazão específica mediana de $0,145 \mathrm{~m}^{3} / \mathrm{h} / \mathrm{m}$ para o Sistema Aquífero Fraturado, que se constitui no principal reservatório subterrâneo da sub-bacia. Observou-se que a vazão específica dos poços varia de forma inversamente proporcional à profundidade dos poços, ou seja, o aumento da profundidade resulta em queda das vazões específicas. Considerando-se as unidades geológicas interceptadas, os valores mais elevados de vazão específica foram observados nas rochas metassedimentares dos grupos Serra de Itaberaba e São Roque, com mediana de $0,168 \mathrm{~m}^{3} / \mathrm{h} / \mathrm{m}$ e $0,153 \mathrm{~m}^{3} / \mathrm{h} / \mathrm{m}$, respectivamente, e menos expressivos para os corpos granitoides, que apresentaram mediana de $0,041 \mathrm{~m}^{3} / \mathrm{h} / \mathrm{m}$.

Abstract: The groundwater is an important source of additional water supply in Juqueri-Cantareira watershed, located in the metropolitan region of São Paulo/Brazil, has being used by large number of users for a variety of purposes. Therefore, this study aims to contribute to the knowledge of the productivity of wells and, respectively, of the aquifer systems. It was evaluated the hydraulic parameters available from 189 wells, which indicate specific yield average of $0,145 \mathrm{~m}^{3} / \mathrm{h} / \mathrm{m}$ for Fractured Aquifer System, which is the main aquifer watershed. It was observed that the specific yield of the wells varies inversely proportional to the depth, i.e. increasing depth results in decrease of the specific yield. Considering intercepted geological units, the highest values of specific yield were observed in the metasedimentary rocks of the Grupo Serra de Itaberaba and Grupo São Roque, with a median of $0.168 \mathrm{~m}^{3} / \mathrm{h} / \mathrm{m}$ and $0.153 \mathrm{~m}^{3} / \mathrm{h} / \mathrm{m}$, respectively, and less expressive for granitic bodies, which had a median of $0.041 \mathrm{~m}^{3} / \mathrm{h} / \mathrm{m}$.

Palavras-chave: produtividade de poços, reservatório subterrâneo, gestão de águas subterrâneas

\footnotetext{
${ }^{1}$ Serviço Geológico do Brasil, rua 148, n 485, Setor Marista, Goiânia/GO, tel. (62) 3240-1438, marcio.abreu@cprm.gov.br

${ }^{2}$ Instituto de Geociências - Universidade de São Paulo, Rua do Lago, 562 - Cidade Universitária, São Paulo - SP, tel. (11) 3091-4216 


\section{INTRODUÇÃO}

A água é um importante recurso para o desenvolvimento socioeconômico da população, sendo encontrada principalmente em reservatórios superficiais e subterrâneos. Conforme destaca a Agência Nacional de Águas - ANA (Agência Nacional de Águas, 2015), a água subterrânea é um componente de grande importância no abastecimento público e privado em inúmeras cidades brasileiras, entretanto, essa importância é contrastada com a deficiência no conhecimento dos reservatórios subterrâneos no país.

As águas subterrâneas são fontes seguras de água durante períodos de seca, menos vulneráveis a contaminação, possuem excelente qualidade natural e, na maioria dos casos, dispensa qualquer tipo de tratamento.

Para uma adequada gestão dos recursos hídricos é fundamental o conhecimento da fonte desse recurso e, segundo Conicelli (2014), ele se torna mais imperativo quando se lida com as águas subterrâneas, pois por ser um recurso invisível, torna-se difícil para as pessoas compreenderem a dinâmica dos aquíferos.

A Bacia Hidrográfica do Alto Tietê (BAT) comporta um dos maiores conglomerados urbanos do mundo, com uma população superior a 18 milhões de pessoas, refletindo na complexa forma de uso e ocupação da terra e do aproveitamento dos recursos naturais. Devido à suas características, o manancial superficial é a principal fonte pública de abastecimento, enquanto que o recurso subterrâneo contribui para o suprimento complementar de água na região, sendo utilizada por grande número de indústrias, condomínio e empreendimentos isolados como suprimento para suas necessidades.

Apesar da importância da água subterrânea como fonte alternativa ao abastecimento público na BAT, são escassas as informações básicas para seu uso adequado, tais como a totalidade dos poços em operação, o perfil dos usuários e os volumes explorados (Hirata e Ferreira, 2001).

Este trabalho tem como objetivo contribuir para o conhecimento dos reservatórios de águas subterrâneas na sub-bacia Juqueri-Cantareira, inserida na BAT, através da avaliação da produtividade dos poços tubulares e suas variações em função dos elementos que influenciam na circulação e acúmulo da água subterrânea.

\section{METODOLOGIA}

\subsection{Localização da Área de Estudo}

A sub-bacia hidrográfica Juqueri-Cantareira conta com uma área de drenagem de aproximadamente $713 \mathrm{~km}^{2}$, inserida na Unidade de Gerenciamento de Recursos Hídricos da Bacia do Alto Tietê (Figura 1). O rio Juqueri nasce no município de Nazaré Paulista e segue pelas cidades de Mairiporã, Franco da Rocha, Caieiras, Francisco Morato, São Paulo, Cajamar, Santana de 
Parnaíba e Pirapora do Bom Jesus. Por fim, deságua no rio Tietê, sendo o principal afluente de sua margem direita. Com cerca de $90 \mathrm{~km}$ de extensão o rio Juqueri tem como afluentes os ribeirões Euzébio e dos Cristais e os córregos Itaim, Moendas, Ajuá, entre outros (Instituto Socioambiental, 2009).

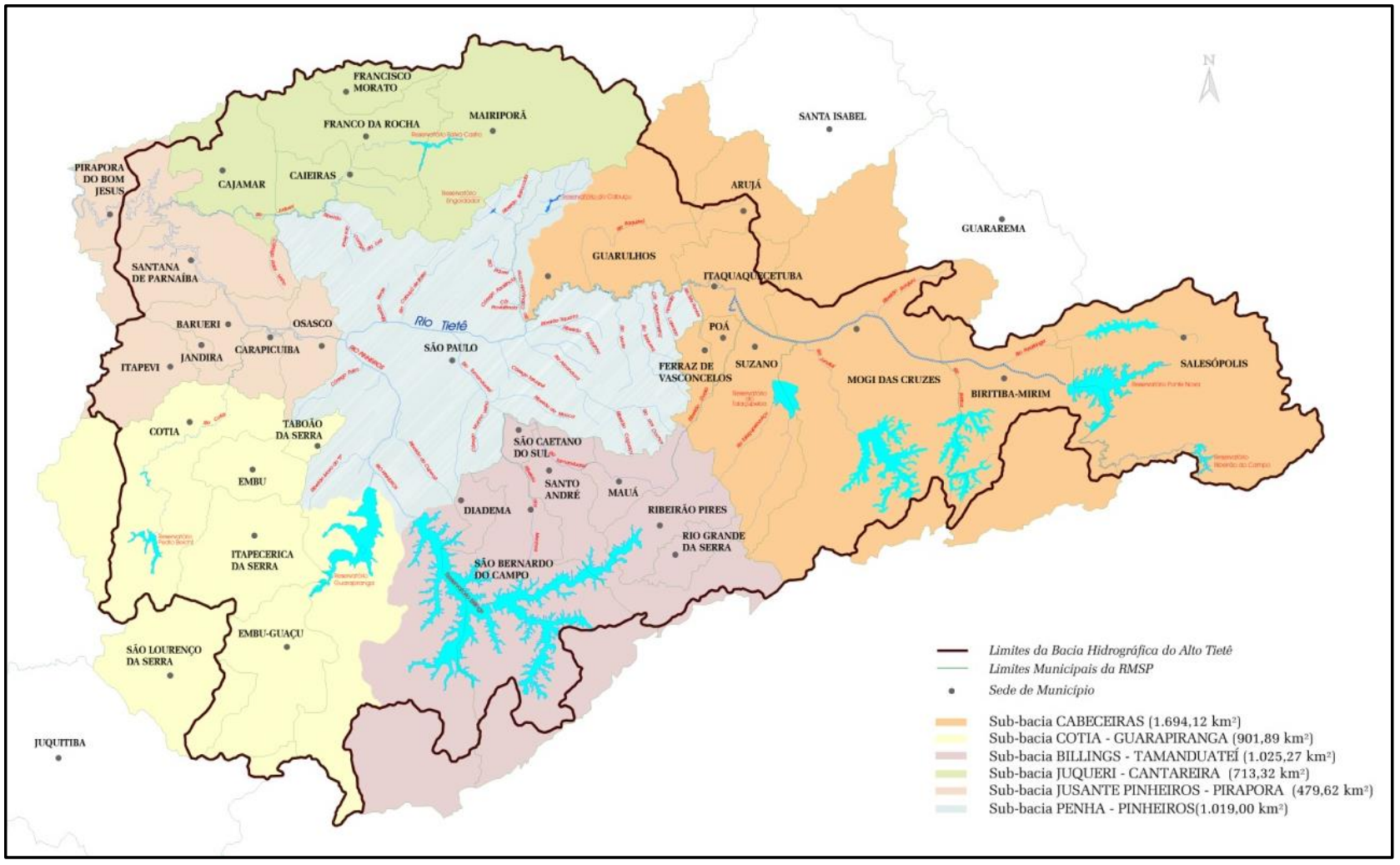

Figura 1. Localização da sub-bacia do Juqueri-Cantareira (Fundação Universidade de São Paulo, 2002)

Possui uma extensa área urbanizada incidente sobre a rede hidrográfica e caracteriza-se por apresentar regimes hidráulicos e hidrológicos extremamente complexos, em virtude das profundas alterações introduzidas por obras hidráulicas e efeitos antrópicos da mais diversa ordem (Fundação Universidade de São Paulo, 2002).

A sub-bacia do Juqueri-Cantareira é uma região de grande importância para o abastecimento público da Região Metropolitana de São Paulo, pois abriga a Barragem Paiva Castro, que é o último reservatório do Sistema Cantareira. Este é o maior sistema de abastecimento público de água na Região Metropolitana de São Paulo (RMSP), responsável por abastecer quase metade de sua população, cerca de 8,1 milhões de habitantes (Instituto Socioambiental, 2009). Apesar da quantidade de água produzida nessa sub-bacia e utilizada para abastecimento não ser volumosa (média de $2 \mathrm{~m}^{3} / \mathrm{s}$ ), a barragem de Paiva Castro é a que recebe toda a água proveniente das quatro represas do Sistema Cantareira. 


\subsection{Caracterização Geral}

O clima na sub-bacia Juqueri-Cantareira é controlado basicamente pelo Oceano Atlântico, a altitude e o relevo, com suas diferentes formas e orientações. Uma das principais características climáticas é a alternância das estações com uma estação quente e úmida e outra fria e relativamente mais seca (SÃO PAULO, 2002). Regionalmente essa alternância explica tanto a ocorrência de fortes impactos pluviométricos, como a existência de longas sequências de períodos secos.

A temperatura na região registra os menores valores médios de temperatura no período entre julho a outubro, registrando temperaturas que variam de $15,8^{\circ} \mathrm{C}$ a $19,0^{\circ} \mathrm{C}$. No verão o valor médio é de $22,4^{\circ} \mathrm{C}$, sendo que os meses de transição apresentam temperaturas médias que vão de $20,3^{\circ} \mathrm{C} \mathrm{em}$ novembro a $19,7^{\circ} \mathrm{C}$ em abril (SÃO PAULO, 2002).

A evaporação média varia entre $104,8 \mathrm{~mm}$ em agosto a um total de $78,2 \mathrm{~mm}$ em julho. A pluviosidade média anual no período entre 1961 a 1990 foi de 1454,8mm, sendo que janeiro representa o mês mais chuvoso com $238,7 \mathrm{~mm}$ e agosto o mês mais seco com 38,9mm (SÃO PAULO, 2002).

\subsection{Geologia e Sistemas Aquíferos na Sub-bacia do Juqueri-Cantareira}

A área de estudo encontra-se predominantemente no domínio das rochas cristalinas do embasamento pré-cambriano, no limite com os sedimentos da Bacia Sedimentar de São Paulo. Segundo o Mapa Geológico do Estado de São Paulo, 1:750.000 (Perrotta et al., 2005) e Bertolo (1996), na sub-bacia do Juqueri-Cantareira ocorrem rochas pertencentes aos grupos São Roque e Serra de Itaberaba, diversos corpos intrusivos de composição granítica e depósitos sedimentares cenozóicos e quaternários.

O Grupo São Roque é composto por rochas de idade neoproterozóica submetidas a um metamorfismo regional de baixo grau, sendo que na área da sub-bacia ocorrem as formações Estrada dos Romeiros (composta por rochas arenosas e pelíticas), Pirapora do Bom Jesus (constituído por rochas carbonáticas) e Boturuna (formada por rochas vulcânicas e arenosas).

O Grupo Serra de Itaberaba é mais antigo que o Grupo São Roque, com idade mesoproterozóica também submetido a um metamorfismo de baixo a médio grau. A litologia desse grupo é representada por rochas metamórficas vulcânicas e sedimentares, que inclui calcissilicáticas, arenosas e pelíticas.

Os corpos graníticos estão distribuídos por toda a área da sub-bacia, possuem idade neoproterozóica e, no geral, estão alongados na direção NE.

Os sedimentos cenozóicos ocorrem em formas de lentes isoladas e restritas associadas à depósitos de leques aluviais a planícies entrelaçadas, compostos por lamitos arenosos a argilosos. Já os sedimentos quaternários estão associados exclusivamente às áreas de várzeas dos cursos d’água 
superficiais da sub-bacia. Esses sedimentos são predominantemente argiloarenosos e possuem espessura limitada, no geral, menores que 10 metros (Bertolo, 1996).

A hidrogeologia da área reflete o sistema geológico existente na unidade de estudo, individualizando-se três sistemas aquíferos principais (Bertolo, 1996): Sistema Aquífero Fraturado, que se subdivide em aquífero A e aquífero B; o Sistema Aquífero Sedimentar, que é subdividido em aquífero Quaternário e aquífero Resende; e o Sistema Aquífero Cárstico, associado às rochas carbonáticas (Figura 2).

O Sistema Aquífero Fraturado é o predominante na área da sub-bacia, composto por rochas cristalinas do embasamento que possuem baixa permeabilidade, onde o fluxo da água subterrânea está associado principalmente às fraturas e falhas existentes nas rochas. A recarga do sistema acontece através da infiltração de águas pluviais e a descarga está associada aos rios e represas próximos.

O Aquífero Fraturado A corresponde à associação de unidades que incluem rochas granitoides e se caracteriza por ser um aquífero do tipo livre, com baixa produtividade. A vazão média individual por poço nesse aquífero é de $9,1 \mathrm{~m}^{3} / \mathrm{h}$ e a capacidade específica média de $0,2 \mathrm{~m} / \mathrm{h} / \mathrm{m}$ para toda a BAT (Fundação Universidade de São Paulo, 2002).

O Aquífero Fraturado B corresponde à associação de rochas predominantemente metassedimentares que incluem quartzitos, micaxistos e metapelitos e caracteriza-se por ser um aquífero do tipo livre. A vazão média individual por poço é de $17,5 \mathrm{~m}^{3} / \mathrm{h}$ e a capacidade específica média é 1,4 m³/h/m (Fundação Universidade de São Paulo, 2002).

O Sistema Aquífero Sedimentar apresenta porosidade primária, é heterogêneo, anisotrópico e possui características de aquífero semiconfinado (Bertolo, 1996). Ocupa as áreas de várzeas dos principais cursos d'água da sub-bacia e corresponde a coberturas neocenozóicas que abrange um conjunto de depósitos colúvio-aluviais, de pequena espessura, descontínuos, sendo explorável apenas por poços cacimba. Possui baixa relevância no volume de água captada no interior dessa sub-bacia. O fluxo de água subterrânea no Sistema Aquífero Sedimentar (aquífero Quaternário) está associado principalmente a um sistema de fluxo local, com direções prováveis em direção às áreas de descargas das sub-bacias locais para as águas mais rasas e, possivelmente, em direção ao rio Juqueri.

O Sistema Aquífero Cárstico está associado às rochas metacarbonáticas, possui caráter livre onde as melhores vazões estão associadas às estruturas de dissolução em conjunto com falhas e fraturas nas rochas, com média a baixa produtividade. A mediana da vazão individual por poço é de $10 \mathrm{~m}^{3} / \mathrm{h}$ e capacidade específica de $0,3 \mathrm{~m}^{3} / \mathrm{h} / \mathrm{m}$. 


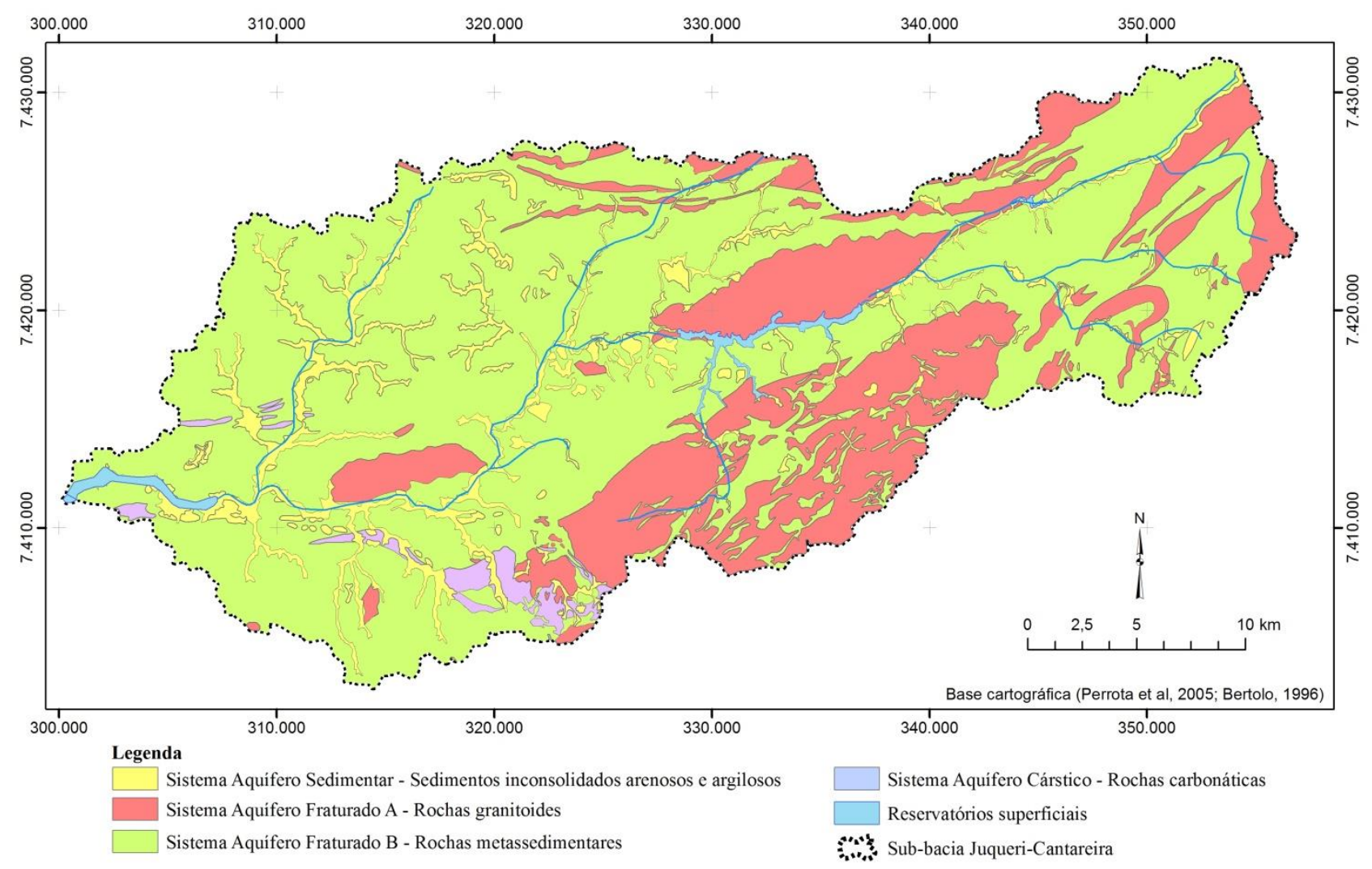

Figura 2. Hidrogeologia da sub-bacia do Juqueri-Cantareira (Bertolo, 1996)

\subsection{Metodologia de Estimativa da Produtividade dos Poços Tubulares}

Os registros dos dados de usuários da água subterrânea foram obtidos no Sistema de Informações de Águas Subterrâneas do Departamento de Águas e Energia Elétrica - DAEE e complementado por informações disponíveis em publicações técnicas relacionadas ao tema.

A avaliação crítica e consistência dos dados se deram pela seleção, digitalização, eliminação de duplicatas e georreferenciamento das informações que posteriormente foram inseridas em um banco de dados unificado, dentro de sistema de informações geográficas (SIG), adotando-se o datum SAD 69 e Fuso 23S.

O parâmetro de produção dos poços tubulares utilizado para avaliar o potencial produtivo foi a capacidade específica, obtido pela relação entre a vazão de teste e o rebaixamento do nível estático. Este parâmetro é um indicador melhor do potencial do aquífero quando comparado à vazão de exploração ou de teste (Fernandes, 2008; Gonçalves et al., 2003). Durante a realização deste trabalho o banco de dados apresentava um total de 189 poços inseridos na área da sub-bacia que possuíam as informações necessárias para o estudo.

Os elementos estruturais que influenciam no acúmulo e circulação da água subterrânea em meios fraturados se expressam em superfície como feições lineares. Sendo assim, foi realizado o levantamento dessas feições na área de estudo para sua representação cartográfica através de 
interpretação de imagens de satélites disponíveis e levantamento de publicações técnicas e científicas associadas ao tema.

Os poços foram plotados em uma base cartográfica digital e, posteriormente, obtidas e inseridas no banco de dados as unidades geológicas em que eles estavam contidos e a distância de cada poço para o lineamento mais próximo.

A análise da variação da vazão específica dos poços tubulares foi realizada com relação aos seguintes elementos: unidades geológicas, profundidade dos poços e distância dos lineamentos cartografados em superfície.

$\mathrm{Na}$ análise sobre a influência das unidades geológicas na produtividade dos poços, estes foram agrupados em três classes distintas, com base nas informações obtidas sobre a geologia da área: Grupo São Roque, Grupo Serra de Itaberaba e granitoides. Ressalva-se que no banco de dados não constavam registros de poços explorando o aquífero sedimentar.

Em relação ao agrupamento frente às estruturas, foram utilizadas as seguintes distâncias para classificação em grupos: poços a menos de 200 metros, poços distantes entre 200 e 500 metros e poços localizados a mais de 500 metros de um lineamento. Por fim, para classificar com base na profundidade foram utilizados os seguintes intervalos: profundidades menores que 100 metros, entre 100 e 150 metros, 150 a 200 metros e acima de 200 metros.

A análise de produtividade foi realizada através do cálculo da mediana e a partir da comparação das curvas de frequência cumulativa das vazões específicas, para os diferentes grupos relacionados anteriormente.

\section{RESULTADOS E DISCUSSÕES}

A análise estatística dos principais parâmetros, abrangendo todos os 189 poços cadastrados, indica vazão específica média de $0,896 \mathrm{~m}^{3} / \mathrm{h} / \mathrm{m}$ e mediana de $0,145 \mathrm{~m}^{3} / \mathrm{h} / \mathrm{m}$. A vazão específica máxima é $39,619 \mathrm{~m}^{3} / \mathrm{h} / \mathrm{m}$ e a mínima é de $0,004 \mathrm{~m}^{3} / \mathrm{h} / \mathrm{m}$, indicando uma grande variação desse parâmetro no conjunto analisado, que é resultado da heterogeneidade e anisotropia dos sistemas aquíferos fraturados. A vazão de captação média e mediana foram, respectivamente, $7,9 \mathrm{~m}^{3} / \mathrm{h}$ e 4,8

$\mathrm{m}^{3} / \mathrm{h}$, com valor máximo de $40 \mathrm{~m}^{3} / \mathrm{h}$. Em relação à profundidade, os resultados da média e mediana apresentam os mesmos valores, 149 e 150 metros, respectivamente, sendo que a perfuração mais profunda foi de 322 metros.

A análise dos dados de vazão específica dos poços de acordo com os grupos analisados para as diferentes unidades geológicas é apresentada na Tabela 1. Conforme pode ser observado, a diferença entre os valores mínimos e máximos da vazão específica chega a ser superior a cinco ordens de grandeza. Por esse motivo, optou-se por adotar o valor da mediana como referência do potencial das unidades aquíferas, visto que a média é fortemente influenciada por valores anômalos. 
O Grupo São Roque é o que apresenta o maior número de poços inseridos (95), seguido pelo Grupo Serra de Itaberaba, com 73 e pelos granitoides, com 21. Observa-se que os poços inseridos nos grupos São Roque e Serra de Itaberaba (que corresponde ao Sistema Aquífero Fraturado B de Bertolo, 1996) possuem produtividade bastante similar, com vazões específicas medianas de 0,168 $\mathrm{m}^{3} / \mathrm{h} / \mathrm{m}$ e $0,153 \mathrm{~m}^{3} / \mathrm{h} / \mathrm{m}$, respectivamente. Já os poços inseridos nos granitoides (Sistema Aquífero Fraturado A) apresentam produtividade bastante reduzida em relação aos outros dois grupos, com mediana da vazão específica uma ordem de grandeza menor, de $0,041 \mathrm{~m}^{3} / \mathrm{h} / \mathrm{m}$.

Tabela 1. Dados estatísticos referentes a vazão específica $\left(\mathrm{m}^{3} / \mathrm{h} / \mathrm{m}\right)$ dos poços tubulares para as diferentes unidades litológicas da sub-bacia do Juqueri-Cantareira

\begin{tabular}{|l|c|c|c|}
\hline & $\begin{array}{c}\text { Grupo } \\
\text { Serra de Itaberaba }\end{array}$ & $\begin{array}{c}\text { Grupo } \\
\text { São Roque }\end{array}$ & Granitoides \\
\hline Número de poços & 73 & 95 & 21 \\
\hline Mediana & 0,153 & 0,168 & 0,041 \\
\hline Média & 1,024 & 0,858 & 0,619 \\
\hline Máximo & 12,105 & 39,619 & 8,929 \\
\hline Mínimo & 0,006 & 0,004 & 0,005 \\
\hline Desvio padrão & 2,227 & 4,186 & 1,949 \\
\hline
\end{tabular}

Ao se avaliar as curvas de distribuição acumulada da vazão específica para esses grupos (Figura 3) nota-se uma similaridade entre os poços inseridos no Grupo São Roque e no Grupo Serra de Itaberaba, com sobreposição das curvas, exceto no trecho final, onde as vazões específicas dos poços inseridos no Grupo Serra de Itaberaba são pouco mais elevadas que do Grupo São Roque. Esses valores mais elevados no trecho final da curva dos poços inseridos no Grupo Serra de Itaberaba resultam em uma média da vazão específica superior para essa unidade $\left(1,024 \mathrm{~m}^{3} / \mathrm{h} / \mathrm{m}\right)$. Já a curva dos poços inseridos nos granitoides encontra-se deslocada para baixo em relação às demais, indicando menor potencial para essa unidade, em conformidade com os dados estatísticos apresentados anteriormente.

Essas informações demostram que, apesar das características reológicas distintas, as litologias que constituem o Grupo Serra de Itaberaba e o Grupo São Roque apresentam similaridades hidrogeológicas, com comportamentos hidráulicos semelhantes, sendo que a primeira pode apresentar vazões específicas pouco mais elevadas. Já os granitoides configuram-se nas unidades menos produtivas na área de estudo. 


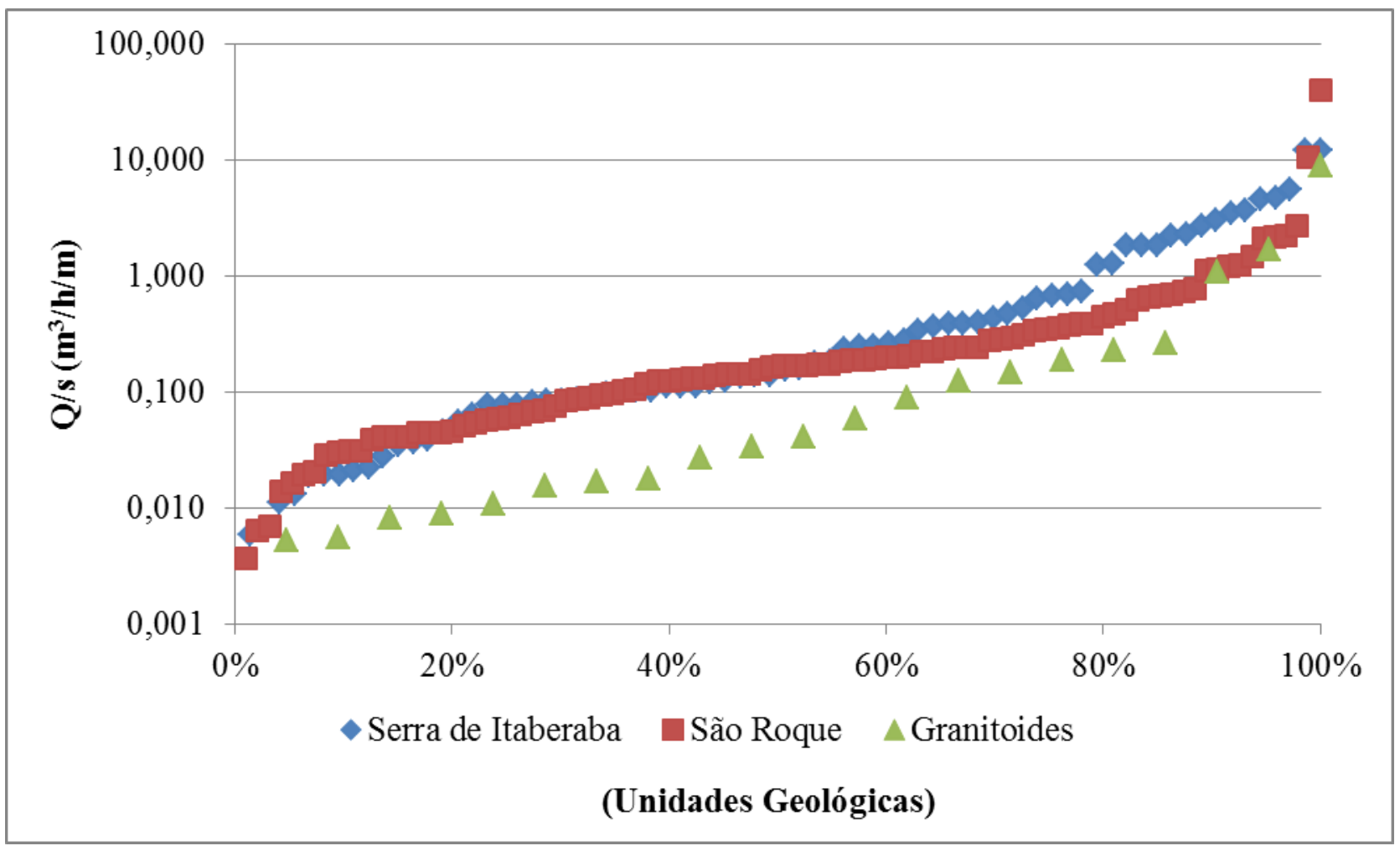

Figura 3. Curva de distribuição acumulada da vazão específica para as diferentes unidades geológicas da sub-bacia do Juqueri-Cantareira

Segundo a literatura (Legrand, 1954; Davis e Turk, 1993; Loiselle e Evans, 1995), a quantidade e a abertura das fraturas tendem a diminuir com o incremento da profundidade, devido à influência da pressão litostática, resultando em um decréscimo da potencialidade dos aquíferos fissurais em maiores profundidades. Considerando que a vazão específica é a razão entre a vazão total e a espessura da zona saturada, se aumentar a profundidade sem aumentar o volume de entrada de água para o poço, a vazão específica irá diminuir.

Essa situação fica evidente nos dados dos poços utilizados nesse estudo, conforme dados apresentados na Tabela 2 e no gráfico da Figura 4, elaborado a partir dos registros de vazão específica para cada intervalo de profundidade.

Tabela 2. Dados estatísticos referentes a vazão específica $\left(\mathrm{m}^{3} / \mathrm{h} / \mathrm{m}\right)$ dos poços tubulares para os diferentes intervalos de profundidade dos poços tubulares

\begin{tabular}{|l|c|c|c|c|}
\hline & $<100$ & 100 a 150 & 150 a 200 & $>200$ \\
\hline Número de Poços & 37 & 56 & 48 & 36 \\
\hline Mediana & 0,676 & 0,143 & 0,118 & 0,045 \\
\hline Média & 2,927 & 0,572 & 0,294 & 0,125 \\
\hline Máximo & 39,619 & 10,626 & 4,651 & 1,194 \\
\hline Mínimo & 0,017 & 0,006 & 0,007 & 0,004 \\
\hline Desvio padrão & 6,887 & 1,482 & 0,709 & 0,230 \\
\hline
\end{tabular}


Os poços com profundidades inferiores a 100 metros são os que apresentam a maior vazão específica mediana, seguida de diminuição expressiva desse parâmetro conforme aumenta a profundidade. O mesmo ocorre quando se considera a vazão específica média.

As curvas de frequência acumulada da vazão específica elaboradas para cada um dos intervalos de profundidades definidos neste trabalho ilustram muito bem a diminuição da produtividade em função do aumento da profundidade dos poços. Essa informação é de grande utilidade para o projeto de poços, pois os custos da perfuração podem ser bastante reduzidos. Devese salientar que essa relação da diminuição da produtividade em função da profundidade ocorre independentemente da litologia atravessada pelo poço.

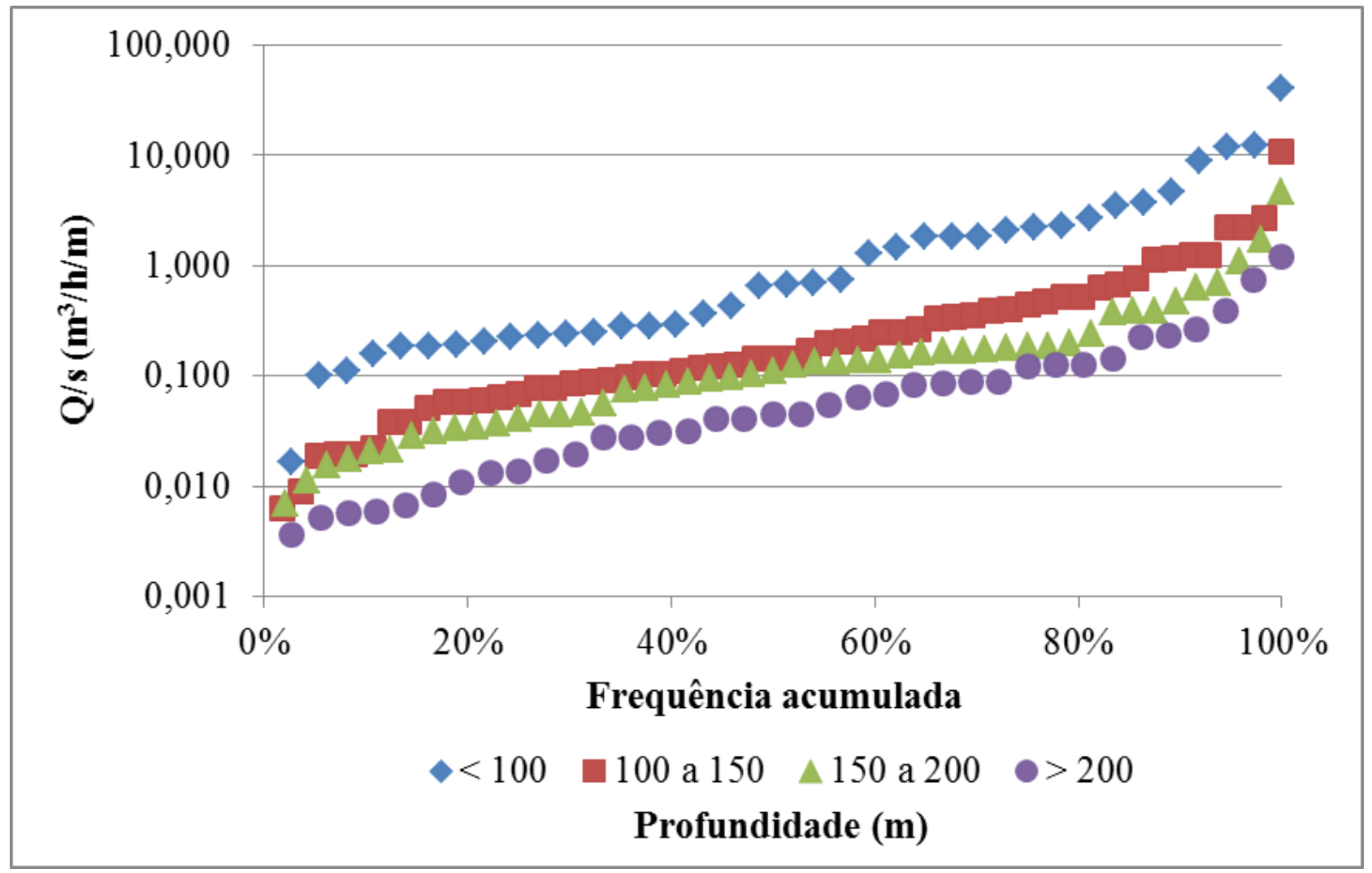

Figura 4. Curva de distribuição acumulada da vazão específica para as diferentes profundidades (em metros) dos poços tubulares

A existência de estruturas abertas é fator condicionante para ocorrência de acúmulo e fluxo da água nessas unidades geológicas existentes na sub-bacia do Juqueri-Cantareira. A partir dessa premissa, pode-se presumir que, para os poços apresentarem alguma produtividade é necessário que estes interceptem alguma estrutura produtiva. Por isso, foi avaliada a influência da proximidade de feições lineares nas vazões específicas dos poços tubulares (Figura 5). 


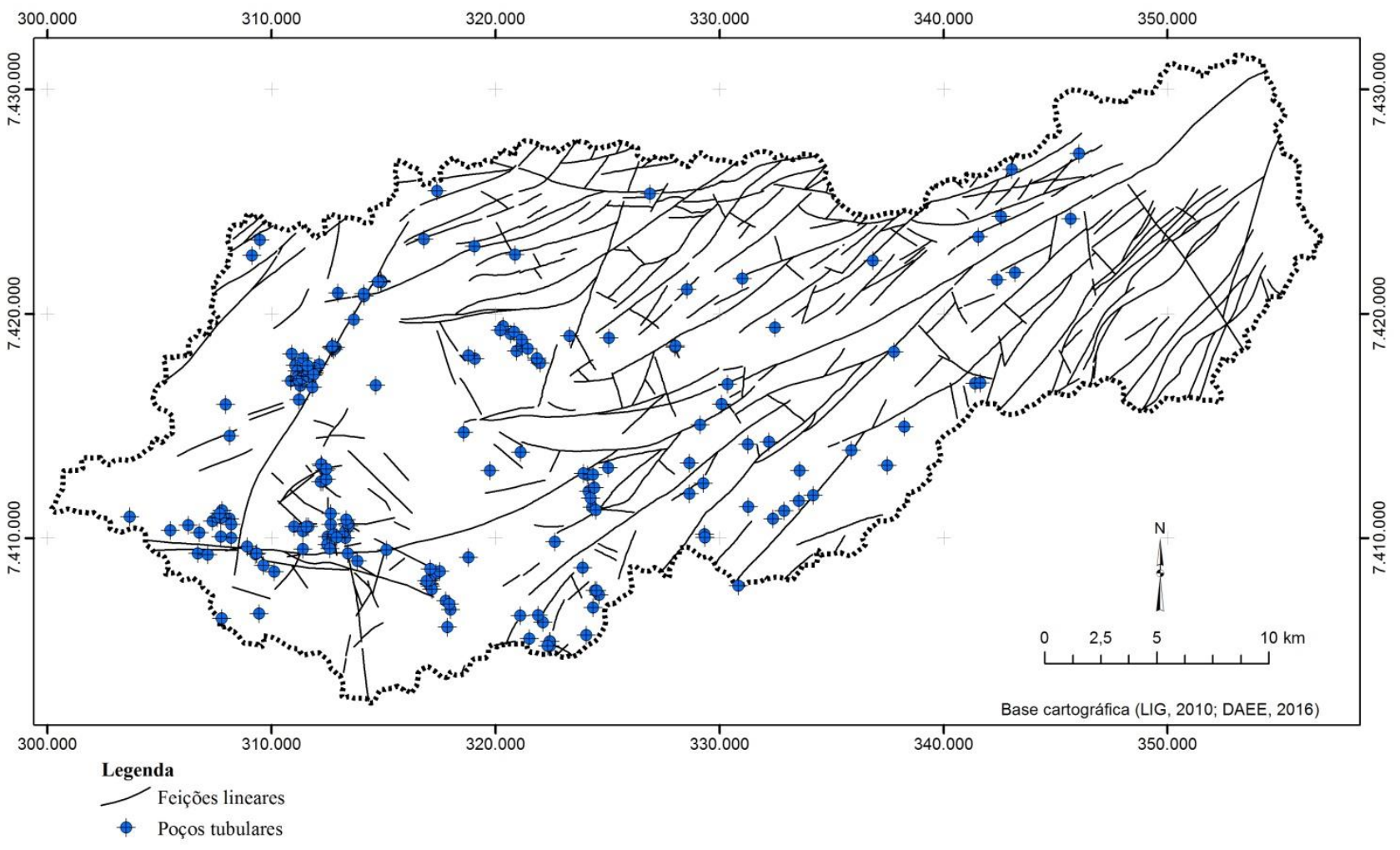

Figura 5. Distribuição espacial dos poços tubulares e feições lineares mapeadas

Conforme pode ser observado na Figura 6, as curvas de frequência acumulada da vazão específica conforme os intervalos de distância utilizados não indicam uma relação direta com esse elemento. As três curvas estão praticamente sobrepostas.

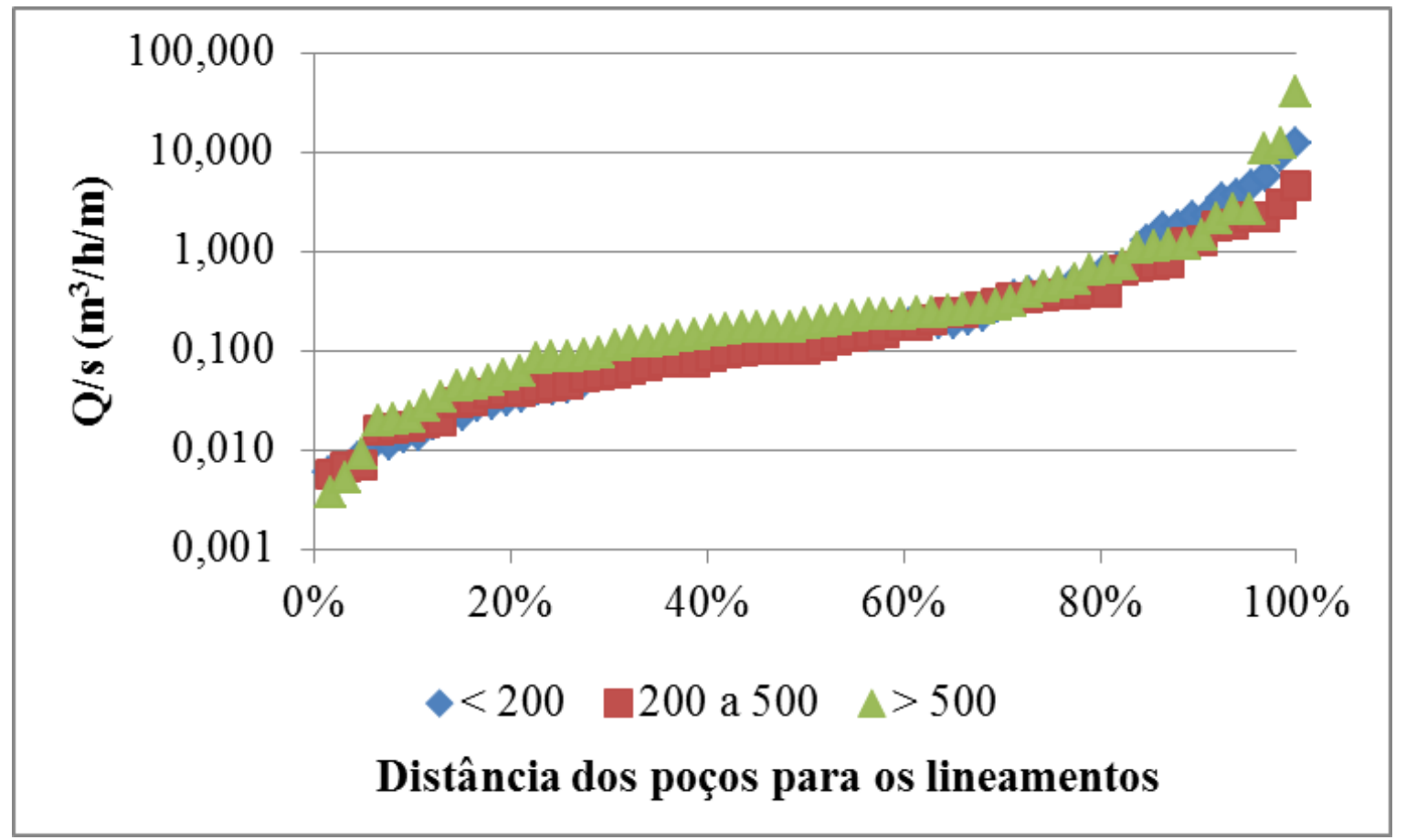

Figura 6. Curva de distribuição acumulada da vazão específica em função da distância (em metros) dos poços tubulares para as feições lineares 
É importante salientar que, segundo Fernandes (2008), para escalas menores que 1:25.000 como a utilizada nesse trabalho (1:100.000), não existe resolução suficiente para afirmar qual ou quais fraturas seccionam o poço, sendo possível apenas inferir a zona de influência da estrutura sobre o poço. Para se identificar a influência das estruturas na variação da produtividade dos poços, recomenda-se um estudo de detalhe com dados adicionais para confirmar essa tendência.

A mediana da vazão específica para os poços localizados a menos de $200 \mathrm{~m}$ de distância dos lineamentos foi de $0,128 \mathrm{~m}^{3} / \mathrm{h} / \mathrm{m}$, para aqueles localizados entre 200 e $500 \mathrm{~m}$ foi de $0,107 \mathrm{~m}^{3} / \mathrm{h} / \mathrm{m}$ e dos poços distantes acima de $500 \mathrm{~m}$ foi de $0,191 \mathrm{~m}^{3} / \mathrm{h} / \mathrm{m}$.

\section{CONCLUSÕES}

A sub-bacia hidrográfica do Juqueri-Cantareira possui cadastrado 189 poços tubulares com informações suficientes para a avaliação da produtividade. Salienta-se que a quantidade de poços existentes na sub-bacia do Juqueri-Cantareira é possivelmente subestimada, pois estudos realizados indicam que cerca de $70 \%$ dos poços existentes na Bacia do Alto Tietê são clandestinos.

A geologia da sub-bacia é caracterizada principalmente pela ocorrência de rochas metamórficas e ígneas, localmente sobrepostas por sedimentos da Bacia Sedimentar de São Paulo e, nas áreas de várzeas das principais drenagens, ocorrem sedimentos inconsolidados.

As rochas metamórficas são representadas essencialmente por metassedimentos dos grupos São Roque e Serra do Itaberaba, enquanto que diversos corpos intrusivos de composição granítica representam as rochas ígneas.

O principal reservatório subterrâneo da sub-bacia, em extensão e número de poços existentes, é o Sistema Aquífero Fraturado, constituído pelas rochas metamórficas e ígneas. Considerando-se a totalidade de poços inseridos no Sistema Aquífero Fraturado, a vazão específica mediana dessa unidade é de $0,145 \mathrm{~m}^{3} / \mathrm{h} / \mathrm{m}$ e a média de $0,896 \mathrm{~m}^{3} / \mathrm{h} / \mathrm{m}$. Foi verificada uma grande variação desse parâmetro nos dados disponíveis, resultante da heterogeneidade e anisotropia desse sistema, cuja circulação e acúmulo de água está condicionada a ocorrência de fraturas abertas.

Os dados de vazão captada indicam média de $7,9 \mathrm{~m}^{3} / \mathrm{h}$ e $4,8 \mathrm{~m}^{3} / \mathrm{h}$, com valor máximo de $40 \mathrm{~m}^{3} / \mathrm{h}$ e a profundidade média dos poços é de 149 metros.

A análise da variação da produtividade em função das diferentes unidades geológicas indica que as rochas do Grupo Serra de Itaberaba e do Grupo São Roque possuem características hidráulicas similares, com vazão específica mediana de $0,168 \mathrm{~m}^{3} / \mathrm{h} / \mathrm{m}$ e de $0,153 \mathrm{~m}^{3} / \mathrm{h} / \mathrm{m}$, respectivamente. Os granitoides apresentam produtividade inferior as outras unidades, com vazão específica mediana de $0,041 \mathrm{~m}^{3} / \mathrm{h} / \mathrm{m}$. Essas variações ocorrem devido às diferentes propriedades mecânicas das rochas existentes na área e suas respostas aos esforços a que foram submetidas. 
De acordo com os resultados obtidos, a produtividade dos poços varia em função da profundidade, ocorrendo diminuição da vazão específica com o seu incremento. Isso indica uma diminuição da abertura das estruturas em profundidades mais elevadas. Os poços com profundidades de até 100 metros possuem vazão específica mediana de $0,676 \mathrm{~m}^{3} / \mathrm{h} / \mathrm{m}$, reduzindo para $0,143 \mathrm{~m}^{3} / \mathrm{h} / \mathrm{m}$ para intervalo entre 100 e 150 metros, $0,118 \mathrm{~m}^{3} / \mathrm{h} / \mathrm{m}$ entre 150 e 200 metros e $0,045 \mathrm{~m}^{3} / \mathrm{h} / \mathrm{m}$ para profundidades superiores a 200 metros.

A análise da influência das estruturas sobre a variação da produtividade não apresentou resultados conclusivos, já que não se verificou variação da vazão específica em função da proximidade das estruturas. Seria prematuro descartar esta possibilidade dada a escala de trabalho utilizada. Um estudo mais detalhado seria recomendável no intuito de relacionar a influência de estruturas com a produtividade.

\section{REFERÊNCIAS}

AGÊNCIA NACIONAL DE ÁGUAS, 2015. Conjuntura dos Recursos Hídricos no Brasil: Informe 2014. Brasília: ANA, 2015. www.ana.gov.br

BERTOLO, R. A. 1996. Relações entre Rios e o Aqüífero Sedimentar da Bacia de São Paulo em Área de Exploração Intensiva de Água Subterrânea. São Paulo, 1996. Dissertação (Mestrado em Ciências) Universidade de São Paulo, São Paulo.

CONICELLI, B. P., 2014. Gestão das Águas Subterrâneas na Bacia Hidrográfica do Alto Tietê (SP). São Paulo, 2012. Tese (Doutorado em Ciências) Universidade de São Paulo, São Paulo.

DEPARTAMENTO DE ÁGUAS E ENERGIA ELÉTRICA. 2016. Pesquisa de dados dos recursos hídricos do Estado de São Paulo. São Paulo. Disponível em: 〈www.daee.sp.gov.br〉. Acesso em: 10 abr. 2016.

DAVIS, S.N., TURK, L.J. 1963. Optimum depths of wells in crystalline rocks. In: National Water Well Exposition, San Francisco, Califórnia.

FERNANDES, A. J., 2008. Aquíferos Fraturados: Uma Revisão dos Condicionantes Geológicos e dos Métodos de Investigação. Revista do Instituto Geológico, São Paulo, 29 (1/2), pp. 49-72.

FUNDAÇÃO UNIVERSIDADE DE SÃO PAULO, 2002. Plano de Bacia Hidrográfica do Alto Tietê - Caderno Técnico Institucional. Caracterização da Propriedade.

GONÇALVES, J. A. C., SCUDINO, P. C. B. E SOBREIRA, F. G., 2003. Domínios Hidrogeológicos no meio fissural do Leste da Zona da Mata-MG e Extremo Noroeste do Estado do Rio de Janeiro. Revista Águas Subterrâneas, vol. 17, n. 1, p 31-40.

HIRATA, R. e FERREIRA, L. M. R., 2001. Os aquíferos da Bacia Hidrográfica do Alto Tietê: disponibilidade hídrica e vulnerabilidade à poluição. Revista Brasileira de Geociências. 31(1): p. $43-50$. 
INSTITUTO SOCIOAMBIENTAL, 2009. Diagnóstico Socioambiental Participativo da Região do Subcomitê Juqueri/Cantareira. 52p.

LEGRAND, H. 1959. Yeld of wells: USA: Division Mineral Resources.

LOISELLE, M., EVANS, D. 1995. Fracture Density Distributions and Well Yields in Coastal Maine. Ground Water, 33(2): 190-196.

LIG (Laboratório de Informática Geológica). 2010. Projeto Alto Tietê. Instituto de Geociências.

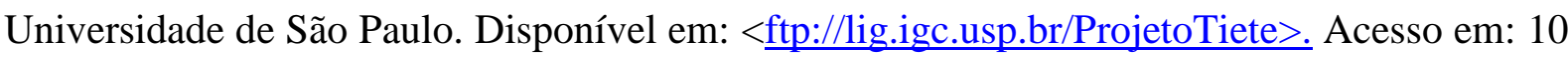
abr. 2016.

PERROTTA, M.M.; SALVADOR, E.D.; LOPES, R.C.; D’AGOSTINO, L.Z.; PERUFFO, N.; GOMES; S.D.; SACHS, L.L.B.; MEIRA, V.T.; LACERDA FILHO, J.V. 2005. Mapa Geológico do Estado de São Paulo, escala 1:750.000. São Paulo: Programa Levantamentos Geológicos Básicos do Brasil, Companhia de Pesquisa de Recursos Minerais.

SÃO PAULO (Município), 2002. Atlas Ambiental do Município de São Paulo. Outorgada por Harmi Takiya. Prefeitura do Município de São Paulo. Secretaria do Meio Ambiente, Secretaria de Planejamento Urbano. 